\title{
Perícia de danos psicológicos no processo judicial
}

\section{Expertise of psychological damage in the judicial process}

\author{
Roberto Moraes Cruz ${ }^{1}$, Saidy Karolin Maciel, Alessandro Vieira dos Reis, \\ Romilda Guilland, Diego Remor Moreira Francisco
}

\begin{abstract}
RESUMO
O objetivo deste estudo foi analisar a perícia do dano psicológico em termos conceituais e metodológicos. O dano psicológico é o resultado de um ou várias experiências traumáticas ou potencialmente danosas para a saúde mental, à expressão da personalidade e à integridade pessoal. Nesse sentido, é crucial a necessidade de investigação do nexo de causalidade ou concausalidade entre essas experiências traumáticas e suas possíveis consequências, seja elas transitórias ou permanentes. O dano psicológico pode ser objeto de indenização, desde que fique caracterizado como uma incapacidade associada a alterações ou perturbações significativas nos tônus psicológico/psicofisiológico, na atividade humoral/afetiva, no equilíbrio emocional da vítima, ou seja, cujas consequências indiquem prejuízos relevantes na autonomia, na capacidade de autorregularão, adesão e integração ao meio social.
\end{abstract}

Palavras-chave: Dano psicológico; Perícia psicológica; Psicologia Jurídica.

\begin{abstract}
The aim of this study was to analyze the expertise of psychological harm in conceptual and methodological terms. Psychological damage is the result of one or more traumatic experiences or potentially harmful to mental health, personality expression and personal integrity. In this sense, it is crucial to investigate the causal link between these traumatic experiences and their possible consequences, whether transitory or permanent. The psychological damage can be the object of compensation, provided that it is characterized as a disability associated with significant changes or disturbances in the psychological/psychophysiological tone, in the humoral/affective activity, in the emotional balance of the victim, that is, the consequences of which indicate relevant losses in autonomy, in the capacity for self-regulation, adherence and integration into the social environment.
\end{abstract}

Keywords: Psychological damage; Psychological expertise; Juridical Psychology.

\footnotetext{
${ }^{1}$ Universidade Federal de Santa Catarina.

*E-mail: robertocruzdr@gmail.com
} 


\section{INTRODUÇÃO}

O termo perícia tem sua origem etimológica no vocábulo peritia que significa habilidade, saber, capacidade para agir de acordo com conhecimentos específicos (ROVINSKI, 2013). Em termos jurídicos, a perícia se insere no contexto das normas processuais, composta de princípios, regras e formalidades legais que disciplinam a natureza e os atos que caracterizam os processos periciais. Nesse sentido, a perícia é caracterizada com um meio de prova, baseada em procedimentos de investigação, de caráter técnico-científico e realizada por profissional especializado (CRUZ, 2019; ROVINSKI, 2019).

A legitimação do papel do psicólogo como perito se encontra no Decreto-Lei 53.664 de 21 de janeiro de 1964, que regulamenta a Lei 4.119 de 27 de agosto de 1962, sobre a profissão do psicólogo. Afirma-se, nesse Decreto, que cabe ao psicólogo, entre outras atribuições, "realizar perícia e emitir pareceres sobre matéria de psicologia". Complementarmente, a Lei Federal 7270, de 1984, estabelece no artigo 145 que: "os peritos comprovarão sua especialidade sobre a matéria que deverão opinar mediante certidão do órgão profissional em que estiverem inscritos"; no caso dos psicólogos, os Conselhos de Psicologia (CRUZ, 2019).

A perícia psicológica é a modalidade da avaliação psicológica aplicada às demandas jurídicas, que tem como objetivo investigar aspectos psicológicos especificados pela autoridade legal no processo judicial (ROVINSKI, 2019). O papel do perito na instância jurídica é de elucidar a existência de matéria psicológica controversa (seja do ponto de vista da vítima ou do réu), o que implica em uma metodologia especializada, baseada em fontes teóricas e empíricas, recursos técnicos válidos e confiáveis e documentação apropriada (CRUZ; MACIEL, 2017).

As principais fontes teóricas e empíricas da perícia psicológica são as contribuições técnicas e científicas oriundas das seguintes áreas do conhecimento psicológico (CRUZ, 2019): a) Avaliação Psicológica, com seus conceitos, métodos e recursos instrumentais utilizados para mensurar características psicológicas, especialmente quando relacionados ao contexto jurídico; b) Psicologia Jurídica e suas respectivas contribuições teóricas-metodológicas sobre a atuação do psicólogo no contexto jurídico/forense e suas peculiaridades técnicas de investigação pericial.

Além dessas, são importantes fontes para o trabalho pericial do psicólogo: a) os marcos legais (legislações específicas, resoluções e códigos normativos e ético- 
profissional) e jurisprudência (decisões judiciais consolidadas em tribunais superiores) que tratam competências e limites do trabalho do perito, assim como de fatos jurídicos e decisões judiciais em que houve a elaboração de prova pericial psicológica; b) códigos de saúde (CID, DSM, CIF), que auxiliam na classificação, especificação e validação de critérios clínicos para a configuração de dano psicológico, em casos concretos.

\section{O conceito de dano psicológico}

O termo dano provém do latim damnu e significa ofensa pessoal, prejuízo moral, prejuízo material causado a alguém pela deterioração ou inutilização de seus bens; ou, ainda, estrago, deterioração, danificação (ROVINSKI, 2013). O dano psicológico pode ser observado sob duas perspectivas: uma proveniente da Psicologia e outra do Direito, mas compartilham o interesse pelo comportamento humano em situações específicas (ROVINSKI, 2013; TRINDADE, 2017).

Em Psicologia, o conceito de dano psicológico se refere a uma deterioração de funções psicológicas e suas expressões comportamentais, resultantes de um ou várias experiências traumáticas ou eventos críticos, que promoveram alterações no equilíbrio emocional, na autonomia e a capacidade de controlar a manifestação de sintomas de transtornos mentais e do comportamento (CRUZ; MACIEL, 2005; CRUZ, 2019). Em termos jurídicos, o dano psicológico resulta de ação deliberada ou culposa de alguém, sob determinadas circunstâncias, e que traz para o vitimado tanto prejuízos morais quanto materiais, face à limitação de suas atividades habituais, sociais ou de trabalho (FREITAS, 2016).

A caracterização do dano psicológico, bem como suas consequências nos processos, judiciais, são geralmente baseadas em provas técnicas elaboradas pelo psicólogo perito. Do ponto de vista jurídico, é possível afirmar que, em muitos casos, o conteúdo dos argumentos de acusação e defesa e das decisões judiciais, nesses casos, são influenciados por conceitos, teorias e pesquisas empíricas psicológicas ou do campo da saúde mental, em geral (ESPINOSA, 2016).

Sociedade e instituições que ignoram as contribuições do perito psicólogo nos processos judiciais, na condição de especialista em matéria psicológica, carecem, de modo geral, de informações técnicas muitas vezes relevantes à compreensão dos casos judicializados, prejudicando a interpretação dos aspectos psicológicos envolvidos na decisão judicial (NONIS, 2017). Por outro lado, a ausência de provas psicológicas periciais, sejam no campo civil ou criminal, podem interferir na suficiência de provas 
técnicas para a investigação de situações ou eventos traumáticos em que há suspeita de dano psicológico associado. Esse aspecto é particularmente importante nos casos de crianças e adolescentes e, mesmo adultos, que apresentam limitações importantes na qualidade de vida, em função do dano psicológico (MACIEL; CRUZ, 2017).

\section{O estado da arte internacional sobre a perícia de danos psicológicos}

Com a finalidade de obter um panorama da produção científica sobre a perícia de danos psicológicos, disponibilizada internacionalmente, foi realizado um levantamento de artigos científicos nas bases de dados Psycnet (American Association of Psychology), BVS (Biblioteca Virtual em Saúde) e Scopus (Elsevier). O algoritmo de busca empregado foi 'psychological damage' expertise. Foram selecionados apenas artigos publicados em periódicos revisados por pares, entre 2017 e 2021, e disponíveis gratuitamente para acesso. O critério de seleção para eleição definitiva dos artigos foi a leitura dos respectivos resumos para confirmar que se tratavam, especificamente, de artigos sobre perícia de danos psicológicos.

Após o processo de filtragem, foram selecionados 13 artigos. Na base de dados da Psycnet foram identificados quatro artigos: Den Uijl (2017); Taheri et al., (2020); Faghihi et al. (2021) e Cations et al. (2020). Na base da BVS, dois artigos: Krahl (2020) e Moura e Zambón (2020). Da base Scopus, sete artigos: Al-Nuaimmi et al. (2018); Maina et al. (2021); Herrán e Biehler (2020); Ring (2017); Clark (2017); Rafferty (2018) e Medeiros et al. (2019). Os artigos foram submetidos a uma análise textual, por meio do software IRAMUTEQ (Interface de $R$ pour les Analyses Multidimensionnelles de Textes et de Questionnaires), com base na frequência das palavras, e os resultados obtidos permitiram elaborar um diagrama de variáveis e fatores que identificam agrupamentos ou classe de informações. 


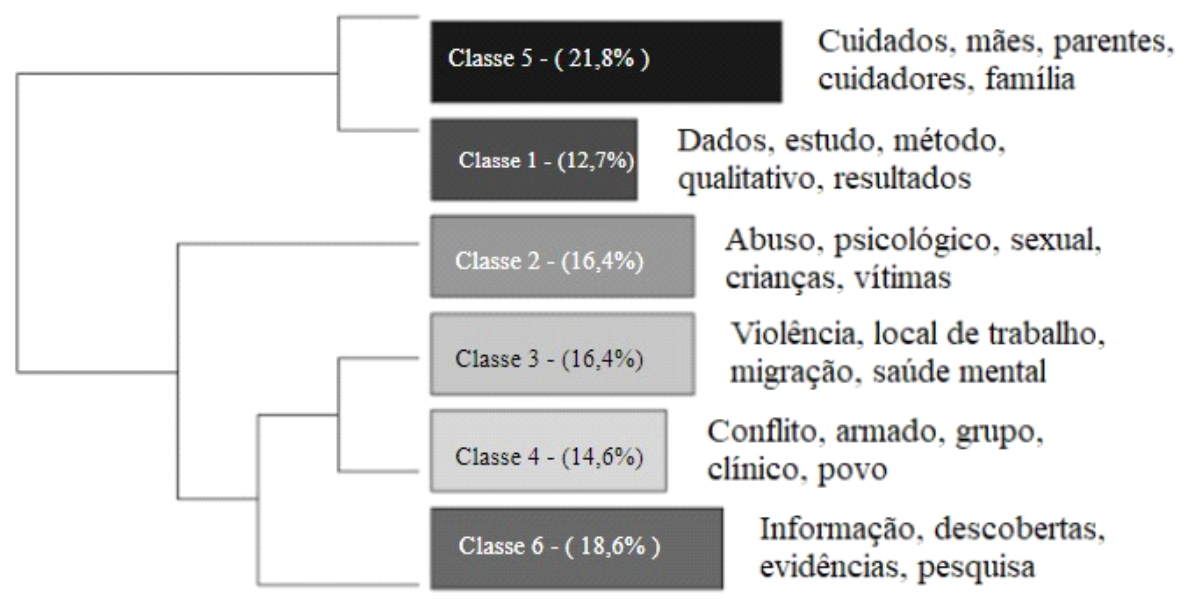

Figura 1 - Diagrama de variáveis e fatores da análise textual dos artigos selecionados.

Fonte: os autores.

Conforme a Figura 1, observa-se um predomínio de estudos qualitativos (classe 1), combinados com estratégias de pesquisa baseadas em evidências (classe 6). Constam como tópicos em destaque nos estudos identificados: abuso sexual infantil (classe 2); violência no local de trabalho, especialmente com imigrantes (classe 3); conflitos armados entre povos e tratamento dado a refugiados (classe 4); problemas no contexto familiar, envolvendo violência contra mulheres, relação entre pais e crianças, idosos etc. (classe 5). Verifica-se, nesses estudos, que a perícia de danos psicológicos se situa no campo da violência contra crianças, no local de trabalho e entre populações vulneráveis (imigrantes e refugiados) e em possibilidades metodológicas periciais.

A Figura 2 apresenta os resultados da análise de similitude, que agrupa visualmente palavras mais frequentes em pares. Essa análise permite identificar os temas mais representativos ou de maior importância nos textos, as palavras mais próximas e distantes umas das outras, ou seja, que guardam relações entre si. 


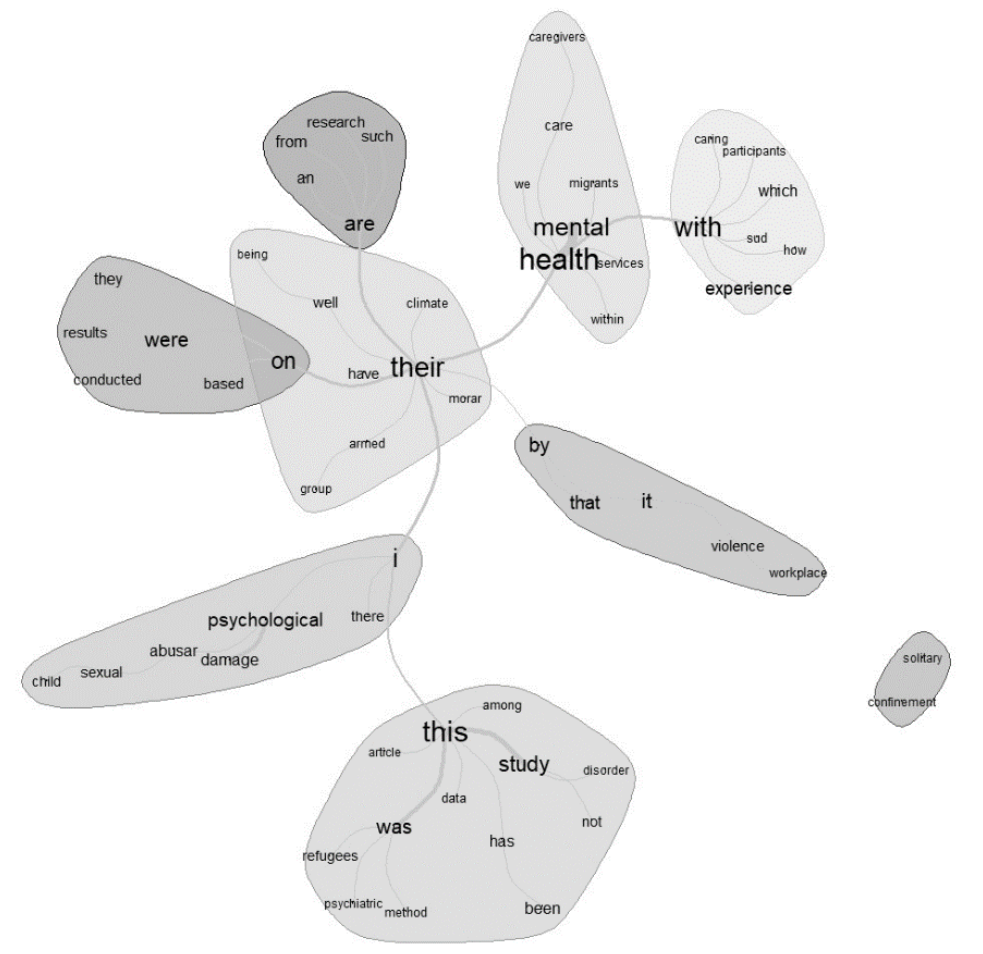

Figura 2 - Análise de similitude dos artigos selecionados

Fonte: os autores.

Na Figura 2 é possível notar nove agrupamentos frequentes de palavras. Destacam-se dois agrupamentos: "saúde mental", incluindo como termos mais frequentes "cuidados", "cuidadores", "migrantes"; "dano psicológico", associado à temática do abuso sexual infantil. Em outro agrupamento, a ideia de dano psicológico se relaciona com "violência" e "local de trabalho", refletindo uma ênfase de estudos de perícia psicológica no âmbito laboral. Por fim, os demais dizem respeito a tópicos como pesquisa, método e resultados de estudos. O menor agrupamento é formado pelos termos "solitária" e "confinamento", numa clara ênfase dos estudos no âmbito criminal.

A análise dos agrupamentos dos 13 artigos selecionados sugere uma tendência internacional em publicar estudos sobre perícia de danos psicológicos baseados em evidências, com abordagem predominantemente qualitativa, e concentrados nas temáticas do abuso infantil, cuidados parentais, violência psicológica, violência no trabalho, comprometimentos à saúde e ao bem-estar, especialmente de populações mais vulneráveis (imigrantes, refugiados, idosos, crianças etc.). Ou seja, situações ou experiências traumáticas que impactam pessoas com menor poder de resposta, reação ou transformação da realidade. 


\section{Perícia de danos psicológicos no processo civil e criminal}

No âmbito dos processos judiciais brasileiros, a perícia de danos psicológicos está enfaticamente relacionada aos casos que envolve possibilidade de reparação/valoração das consequências de acontecimentos traumáticos, especialmente nos casos de abusos, violações, maus tratos, conflitos matrimoniais, assédio moral, acidentes de trânsito. No âmbito do Direito Penal, tendo e vista a noção de crime, criminalidade e de periculosidade uma das funções da caracterização do dano psicológico é a possibilidade de indenizações decorrentes do fato traumático, o que envolve a demonstração de nexo de causalidade

Do ponto de vista da investigação clínica e pericial, a caracterização do dano psicológico envolve a identificação de alguns elementos ou um conjunto de alterações significativas no comportamento e no funcionamento global da pessoa, que restringem e comprometem o tônus psicológico e a capacidade de agir, dentre os quais (CRUZ; MACIEL, 2005): a) na qualidade do sono, alimentação e de outros hábitos regulares; b) na atenção, concentração, memorização, compreensão e tomada de decisão; c) nos estados emocionais, com o aumento da sensibilidade e irritabilidade; d) nas relações afetivas, em geral; e) na autoestima, com a manifestação de desconforto, insegurança, desmotivação e presença de distresse prolongado; e) na autonomia, com limitações na capacidade de adaptação ou enfrentamento de situações; f) na qualidade de vida, em geral.

A caracterização do dano psicológico depende da magnitude do comprometimento à saúde produzido pelo ato ilícito, das consequências para as pessoas que estão diretamente envolvidas com aquela que sofreu o dano. Ou seja, depende do grau da extensão dos efeitos do dano, da sua extensão, do custo social e econômico e da possibilidade de tratamento e reabilitação (CRUZ; MACIEL, 2005; DARAY, 2006). No diagnóstico de dano psicológico, alguns dos critérios devem ser levados em consideração:

- A existência de histórico de morbidez pregressa ou simultânea aos fatos examinados, sua possível relação com o desfecho atual e demais fatores do ambiente (familiar, social e de trabalho) ao qual o indivíduo se expôs. Inclui, ainda, a possibilidade de verificação de trauma direto, sem histórico clínico pregresso relevante;

- Os critérios para caracterização de dano psicológico/psíquico referidos na Classificação Internacional de Doenças, na Classificação Internacional de Funcionalidade, Incapacidade e Saúde ou, ainda, no Manual Diagnóstico e Estatístico de Transtornos Mentais, em suas versões atualizadas, verificando suas especificidades no caso concreto; 
- A temporalidade dos sintomas ou quadro clínico de transtorno mental identificado (transitoriedade ou permanência a longo termo);

- A possibilidade de estabelecimento de nexo causal/concausal (relação de determinação) entre as condições psicológicas do(s) periciado(s) e eventos/experiências danosas ou traumáticas alegadas pela vítima.

O dano, no Direito, ocorre quando em desfavor de outrem é realizado um ato culposo ou danoso, e como consequência deste ato um bem juridicamente tutelado é lesado, promovendo perdas de natureza patrimonial ou extrapatrimonial, gerando assim a responsabilidade civil (STOCO, 2007; SANTOS, 2020). Esse aspecto está tutelado no art. $7^{\circ}$, inciso XXVIII, da Constituição da República Federativa do Brasil (BRASIL, 1988), assim como está regulamentado nos termos dos artigos 186 e 927 do Código Civil (CC).

O dano de natureza patrimonial refere-se às perdas materiais ou ainda em razão de lucros cessantes, quando o sujeito deixa de receber um valor monetário habitual por consequência do dano sofrido, a exemplo da remuneração. O dano extrapatrimonial, ocorre quando existe uma violação de um bem imaterial da vítima, podendo ser a imagem, dignidade, sofrimento, intimidade, pois atinge uma dimensão íntima da pessoa (TRINDADE, 2017; DELGADO, 2018). O dano extrapatrimonial, por sua vez, tem como espécie o dano moral, o dano estético, o dano existencial, o dano decorrente da perda de uma chance e o dano psicológico. Apesar da separação técnica entre dano moral e dano psicológico, a doutrina e a jurisprudência não se encontram sedimentadas, já que grande parte dos doutrinadores compreendem o dano moral como gênero e o dano psicológico como uma espécie deste (TRINDADE, 2017).

O dano psicológico, como espécie do dano extrapatrimonial, pode ser caracterizado quando decorre deste uma incapacidade, comprometimento psicológico ou adoecimento mental (CRUZ; MACIEL, 2005; TRINDADE, 2017). Para tanto, a noção jurídica de dano pressupõe uma relação de causalidade (condição necessária e suficiente para produzir os efeitos) ou de concausalidade (condição necessária, mas não única ou suficiente para produzir os efeitos na vítima) entre os eventos/experiências traumáticas (ofensivos à integridade e/saúde mental da vítima) e suas consequências (ARCE, FARIÑA; VILARINO, 2015; PUHL et al., 2017). Assim, o dano psicológico é definido como sendo extrapatrimonial, mas não necessariamente de natureza moral. Nesse sentido, é possível dizer que o dano psicológico é perfeitamente caracterizável e avaliável, haja 
vista, que os comprometimentos psicológicos são demonstráveis (ex: alterações perceptivas, de humor, quadros clínicos, tentativas de suicídio, dentre outros).

Danos psicológicos, em geral, afetam várias dimensões da vida da pessoa - afetiva, relacional, sexual, laboral - conforme a fase de desenvolvimento em que se encontravam quando da ocorrência dos eventos traumáticos (ECHEBURÚA; CORRAL; AMOR, 2002). Suas consequências podem se estender por um período prolongado e, em função disso, é relevante dispor de serviços de assistência psicológica/psiquiátrica para auxiliar no devido tratamento, nesses casos (MUÑOZ, 2013).

Para analisar os danos psicológicos passíveis de responsabilização cível e criminal, é importante considerar os tipos de violência intrapessoal e interpessoal que interferem na caracterização dos comprometimentos psicológicos ou psíquicos. Para a Organização Pan-Americana da Saúde/Organização Mundial da Saúde (OPAS/OMS, 2003) diversos fatores podem colocar em risco a saúde mental das pessoas, dentre as quais, a violência contra a dignidade humana, uma expressão da violação dos direitos humanos, e aquelas relacionadas às condições de trabalho.

Em relação a violência contra a dignidade/violação dos direitos humanos, a Lei 13.431/2017 estabelece o sistema de garantia de direitos da criança e do adolescente vítima ou testemunha de violência. Além disso, tipifica os tipos de violências em: física, psicológica, sexual e institucional. É considerada violência física toda ação infligida à pessoa, que ofenda sua integridade ou saúde corporal ou que lhe cause sofrimento físico (BRASIL, 2017).

A violência psicológica contra a criança ou o adolescente engloba qualquer conduta de ameaça, humilhação, manipulação, negligência, agressão verbal, exploração ou intimidação sistemática que possa comprometer seu desenvolvimento psíquico ou emocional. A violência sexual é caraterizada quando ocorre uma conduta que constranja a pessoa a praticar ou presenciar conjunção carnal ou qualquer outro ato libidinoso, inclusive exposição do corpo em foto ou vídeo por meio eletrônico. E, quando uma pessoa que representa uma instituição pública ou conveniada gerar revitimização, estará cometendo a denominada violência institucional (BRASIL, 2017).

Toda violência gera sérios prejuízos ao desenvolvimento das crianças e adolescentes, com repercussões cognitivas, emocionais, comportamentais, físicas e sociais que se estendem até a vida adulta (SCHAEFER et al., 2018). Como os sintomas gerados pela violência sofrida podem ser também identificados em outras patologias, cabe 
ao psicólogo perito determinar o nexo causal/concausal entre o tipo de violência sofrida e as repercussões psicológicas geradas.

É possível identificar que o dano psicológico está diretamente associado ao dano moral, em que os argumentos expostos demonstram que o objetivo da aplicação do estabelecimento de um valor referente ao dano é de reparação com caráter punitivo e, também, compensatório. Os critérios de fixação dos danos morais são considerados subjetivos, ficando ao arbítrio do juiz sua quantificação e fixação. Sendo assim, quanto mais caracterizado ficar o prejuízo psicológico em decorrência do evento, mais será possível ao juiz estabelecer um valor indenizatório com base nos conhecimentos sobre o dano psicológico.

No âmbito criminal, o dano psíquico abarca o conceito de trauma em razão de uma conduta identificável, ou seja, um ou mais atos de violência (SANTOS, 2019). O trauma na medicina é descrito por meio de lesões, ferimentos, cortes e queimaduras. Mas, no contexto forense, muitas vezes, não há evidências físicas ou biológicas do ato de violência (HOHENDORFF; HABIGZANG, 2014). Nesse caso, ao avaliar o dano psicológico, deve-se ponderar que o trauma psicológico relacionado a atos de violência difere do estresse do cotidiano diário, em razão de sua intensidade, contexto e frequência.

O conceito de dano psicológico, no contexto criminal, faz alusão a desequilíbrios psicológicos derivados da exposição da pessoa a uma situação de vitimização criminal (psicopatologia traumática). É preciso diferenciar, nesse sentido, os conceitos de dano psicológico e de dano imaterial. O primeiro se refere às consequências psicológicas derivadas do crime, submetido a uma base empírica e mensurável e, portanto, objeto de investigação pericial. O segundo, por sua vez, se refere ao sofrimento da pessoa decorrente do dano a bens imateriais como a honra ou a liberdade, condições muitas vezes imprecisas de determinar de forma objetiva e, portanto, passível de avaliação pelo juiz e não pelo especialista (ESBEC; ECHEBURÚA, 2016).

Nos casos de violência contra crianças e adolescentes, pode-se levar tempo até que os casos sejam identificados. Quando a criança começa a demonstrar que é vítima de violência, o agressor, muitas vezes, passa a intimidá-la, para que não revele, assim, mantém em segredo os atos de violência praticados e isola a criança/adolescente do seu meio social (HOHENDORFF; HABIGZANG, 2014). Nesses casos, o tempo decorrido entre o ato praticado até o momento da revelação de um ato de violência, somada a distância temporal para a realização da avaliação psicológica, gera desafios à identificação de atos de violência. 
No âmbito pericial, é importante que o(a) psicólogo(a) tenha conhecimentos sobre o desenvolvimento infantil e as repercussões negativas geradas por cada tipo de violência, para analisar como era o comportamento da criança, antes de se tornar vítima, e comparálo com aquele apresentado após a violência sofrida. Crianças com vivência de violência em mais de um contexto (escolar, comunitário e doméstico), seja por negligência dos pais ou por bullying praticado por colegas, apresentam maior chance de desenvolvimento de transtorno do estresse pós-traumático, da mesma forma com as crianças vítimas de abuso sexual (XIMENES; OLIVEIRA; ASSIS, 2009).

Crianças e adolescentes vítimas de violência tendem a apresentar dificuldades no âmbito escolar. Dentre as quais, desatenção, isolamento, alterações emocionais, mudanças significativas de comportamento (HABIGZANG, 2008). Contudo, na maioria dos casos, o diagnóstico baseado nos sintomas psicológicos não diferencia de forma confiável as crianças vítimas de violência daquelas das que não são vítimas (BENIA, 2015). Considerando a dificuldade para estabelecer o nexo entre situações de violência e dano psicológico, é importante levar em conta, inicialmente, o tipo de violência vivenciada, a cronicidade, a severidade e as circunstâncias temporalmente associadas (SCHAEFER et al., 2018). E, em um segundo momento, avaliar as dimensões: a) cognitiva; b) emocional, c) condutas associadas à violência; d) nexo de causalidade entre a violência e os prejuízos sofridos (SANTOS, 2019).

Soria (2005) e Muñoz (2013) utilizam o critério cronológico para descrever a evolução do dano psíquico, derivado de uma situação de vitimização criminal. Consideram que o período mais adequado para o perito avaliar o dano psíquico é em torno de 3-4 meses após o ato criminoso. Esse lapso de tempo facilita uma avaliação adequada do curso e prognóstico de possível quadro clínico. A cristalização da sequela psicológica costuma se expressar, do ponto de vista psicopatológico, pelo aparecimento de traços de desajuste de personalidade que dificultam a adaptação da pessoa ao seu ambiente, especialmente em função da dependência emocional, hostilidade e isolamento social.

\section{Conclusão}

A perícia psicológica é uma modalidade de avaliação psicológica e, portanto, constitui um processo de investigação técnico-científica de busca de evidências acerca de fatos, situações ou problemas que exijam uma leitura especializada em termos psicológicos. A perícia psicológica é presença recorrente nas práticas contemporâneas de 
constituição de prova para a administração da justiça e deliberação de mecanismos indenizatórios e compensatórios às vítimas de ofensas, agressões e abusos.

A perícia de dano psicológico no processo judicial reflete a necessidade de investigar alterações significativas na personalidade, no comportamento e no funcionamento global da pessoa, que restringem ou comprometem o tônus psicológico e a capacidade de agir em diferentes esferas da vida. Basicamente, a investigação de dano psicológico busca revelar três aspectos essenciais: a) o comprometimento funcional da pessoa, em termos de execução de atividades habituais; b) as alterações clinicamente significativas que afeta em maior ou menor grau a adaptação/funcionamento da pessoa para as diversas áreas de sua vida (pessoal, social, familiar ou de trabalho); c) à estabilização e à consolidação desse comprometimento funcional, denominado de sequelas psicológicas.

É importante salientar que para o diagnóstico do dano psicológico é necessário que seja caracterizada a incapacidade e/ou um prejuízo no desempenho da pessoa, que não existia anteriormente e, nesse caso, pode ser objeto de indenização. Por meio da perícia psicológica, voltada à avaliação do dano, os juízes podem obter maiores informações sobre a natureza e as repercussões psicológicas dos prejuízos decorrentes. Cabe afirmar que a prova técnica pericial, produzida pelo psicólogo perito, tem o condão de contribuir na convicção do julgador e, assim, auxiliar na compreensão do caso e na decisão judicial.

É fundamental compreender que a atuação do perito e os resultados obtidos no processo pericial impactam na vida do periciado e no seu entorno. É essencial que o psicólogo reconheça a extensão do poder que lhe é outorgado quando realiza ou participa de processos periciais e confecciona seus respectivos documentos psicológicos. A adotar uma postura responsável e ética, assim como buscar evidências válidas e pertinentes à compreensão dos aspectos psicológicos envolvidos no litígio judicial, são compromissos imprescindíveis à efetivação de direitos e garantias dos envolvidos. 


\section{REFERÊNCIAS}

AL-NUAIMI, S.; ALDANDASHI, S.; EASA, A. K. S.; SAQQUR, M. Psychiatric morbidity among physically injured Syrian refugees in Turkey. Comprehensive psychiatry, v. 80, p. 34-38, 2018.

ARCE, R. Evaluación del daño psicológico: Psicometría, entrevista y técnica forense. In: CARBONELL, E.; PINEDA, D.; NOVO, M. (Eds). Psicología jurídica: Ciencia y profesión. Santiago de Compostela: Sociedad Española de Psicología Jurídica y Forense, 2018, p. 236.

ARCE, R.; FARIÑA, F.; VILARIÑO, M. Daño psicológico en casos de víctimas de violencia de género: estudio comparativo de las evaluaciones forenses. Revista Iberoamericana de Psicología y Salud, v. 6, n. 2, p. 72-80, 2015.

BENIA, L. R. A entrevista de crianças com suspeita de abuso sexual. Estudos de Psicologia (Campinas), v. 32, n. 1, p. 27-35, 2015.

BRASIL. Constituição da República Federativa do Brasil de 1988. Planalto.gov.br. Disponível em: <http://www.planalto.gov.br/ccivil_03/constituicao/constituicao.htm>.

BRASIL. Decreto No 53.464, de 21 de janeiro de 1964. Regulamenta a Lei $n^{\circ} 4.119$, de 27 de agosto de 1962, que dispõe sobre a profissão de psicólogo Disponível em: http://www.planalto.gov.br/ccivil_03/decreto/1950-1969/d53464.htm.

BRASIL. Lei n. 13.105, de 16 de março de 2015. Planalto.gov.br. Disponível em: <http://www.planalto.gov.br/ccivil_03/_ato2015-2018/2015/lei/113105.htm\#art371>.

BRASIL. Lei n. 7.270, de 10 de dezembro de 1984. Diário Oficial da União, Brasília; 1984. Disponível em: http://www.planalto.gov.br/ccivil_03/leis/1980-1988/17270.htm.

BRASIL. Lei no 13.431, de 4 de abril de 2017. Planalto.gov.br. Disponível em: <http://www.planalto.gov.br/ccivil_03/_ato20152018/2017/lei/L13431.htm>.

CATIONS, M.; LAVER, K. E.; WALKER, R.; SMYTH, A.; FERNANDEZ, E.; CORLIS, M. The case for trauma-informed aged care. International journal of geriatric psychiatry, v. 35, n. 5, p. 425-429, 2020.

CLARK, Andrew B. Juvenile solitary confinement as a form of child abuse. The journal of the American Academy of Psychiatry and the Law, v. 45, n. 3, p. 350357, 2017.

CRUZ, R. M. Perícia psicológica trabalhista. In: HUTZ, C. S., BANDEIRA, D. R., TRENTINI, C. M.; ROVINSKI, S. L. R.; MEDEIROS DE LAGO, V. (orgs.). Avaliação Psicológica no Contexto Forense. Porto Alegre: Artmed, 2019, p. 143.

CRUZ, R. M.; MACIEL, S. Perícia de danos psicológicos em acidentes de trabalho. Estudos e Pesquisas em Psicologia, v. 5, n. 2, p. 120-129, 2005.

DARAY, H. Daño Psicológico. Buenos Aires: Astrea, 2006. 
DELGADO, M. G. Curso de direito do trabalho. 17. ed. São Paulo: LTr, 2018.

DEN UIJL, E. Ervaring is de beste leermeester. Het inzetten van ervaringsdeskundigheid bij vechtscheidingen. Journal of Social Intervention: Theory and Practice, v. 26, n. 4, p. 47-57, 2017.

ECHEBURÚA, E.; CORRAL, P.; AMOR, P. Evaluación del daño psicológico en las víctimas de delitos violentos. Psicothema, p. 139-146, 2002.

ESBEC, E.; ECHEBURÚA, E. Mala praxis en Psicología Clínica y Forense a la luz de los tribunales de justicia españoles: un análisis exploratorio. Psicología Conductual: Revista Internacional Clínica y de la Salud, V. 24, n.1, p. 179-196, 2016.

ESPINOSA, A. Prueba pericial psicológica. In: L. Rodríguez-Cely (Coord.). Psicología Jurídica y Forense: Debates, propuestas e investigaciones. Madrid: Tirant, 2016, p. 278.

FAGHIHI, M.; FARSHAD, A.; ABHARI, M. B.; AZADI, N.; MANSOURIAN, M. The components of workplace violence against nurses from the perspective of women working in a hospital in Tehran: a qualitative study. BMC women's health, v. 21, n. 1, p. $1-13,2021$

FREITAS, A. G. A prova pericial no novo código de processo civil brasileiro (Lei 13.105/15) - Análise sintética dos principais pontos alterados. RBOL - Revista Brasileira de Odontologia Legal, p. 118-122, 2016.

HERRÁN, K; BIEHLER, D. Analysis of environmental migrants and their mental health in strengthening health systems. F1000Research, v. 9, n. 1367, p. 1367, 2020.

HOHENDORFF, J. V.; HABIGZANG, L. F. Atuação do profissional da psicologia na avaliação e intervenção em situações de violência sexual contra adolescentes. In: HABIGZANG, L. F.; DINIZ, E.; KOLLER, S. H. Trabalhando com adolescentes: teoria e intervenção psicológica. Porto Alegre: Artmed, 2014.

KRAHL, G. Was bleibt? Gutachterliche Aspekte psychischer Unfallfolgen. Der Unfallchirurg, v. 124, n. 1, p. 34-39, 2021.

MACIEL, S. K.; CRUZ, R. Violência psicológica contra crianças nas interações familiares: problematização e diagnóstico. In: ROVINSKI, S. L. R. Psicologia jurídica: perspectivas teóricas e processos de intervenção. São Paulo: Vetor, 2017.

MAINA, G.; OGENCHUK, M.; PHANEUF, T.; KWAME, A. "I can't live like that": the experience of caregiver stress of caring for a relative with substance use disorder. Substance Abuse Treatment, Prevention, and Policy, v. 16, n. 1, p. 1-9, 2021.

MEDEIROS, E. SHRESTHA, P. N.; GAIRE, H.; ORR, D. M. Life after armed group involvement in Nepal: A clinical ethnography of psychological well-being of former "child soldiers" over time. Transcultural psychiatry, v. 57, n. 1, p. 183-196, 2020.

MOURA, A. G. L. P.; ZAMBÓN, S. P. La Confiabilidad de las Técnicas Proyectivas Gráficas en la Pericía Psicológica del Abuso Sexual. Subjetividad y Procesos Cognitivos, v. 24, n. 1, p. 42-68, 2020. 
MUÑOZ, J. M. La evaluación psicológica forense del daño psíquico: propuesta de un protocolo de actuación pericial. Anuario de Psicología Jurídica, v. 23, n. 1, p. 61-69, 2013.

NONIS, B. N. T. La prueba pericial en materia de Psicologia. In: PICÓ I JUNOY, J.; MIRANDA VÁZQUEZ, C. Peritaje y prueba pericial. España: Biblioteca de Derecho procesal, 2017.

Organización Panamericana de la Salud/ Organización Mundial de la Salud OPAS/OMS, 2003). Informe mundial sobre la violencia y la salud. Resumen. Washington DC: Oficina Regional para las Américas de la Organización Mundial de la Salud, 2003.

PUHL, S. M., DE LOS ÁNGELES IZCURDIA, M., OTEYZA, G., \& MAERTENS, B. H. G. Peritaje psicológico y daño psíquico. Anuario de Investigaciones, v. 24, p. 251260, 2017.

RAFFERTY, Y. Mental health services as a vital component of psychosocial recovery for victims of child trafficking for commercial sexual exploitation. American journal of orthopsychiatry, v. 88, n. 3, p. 249, 2018.

RING, S. The victim of historical child sexual abuse in the Irish Courts 1999-2006. Social \& Legal Studies, v. 26, n. 5, p. 562-580, 2017.

ROVINSKI, S. L. R. Avaliação de Dano Psíquico na Área Cível. In: HUTZ, C. S.; BANDEIRA, D. R.; TRENTINI, C. M.; ROVINSKI, S. L. R.; MEDEIROS LAGO, V. (orgs.) Avaliação Psicológica no Contexto Forense. Porto Alegre: Artmed, 2019, p. 364-375.

ROVINSKI, S. L. R. Fundamentos da perícia psicológica forense. São Paulo: Vetor, 2013.

SANTOS, C. L. Dano psíquico. FORO. Revista de Ciencias Jurídicas y Sociales, Nueva Época, v. 22, n. 1, p. 255-265, 2020.

SCHAEFER, L. S.; BRUNNET, A.; LOBO, B. O. M.; CARVALHO, J. C. N.; KRISTENSEN, C. H. Indicadores psicológicos e comportamentais na perícia do abuso sexual infantil. Temas em Psicologia, v. 26, n. 3, p. 1467-1482, 2018.

STOCO, R. Tratado de responsabilidade civil: doutrina e jurisprudência. 7 . ed. São Paulo: Editora Revista dos Tribunais, 2007.

TAHERI, M.; TAGHIZADEH, Z.; JAFARI, N., TAKIAN, A. Perceived strategies to reduce traumatic childbirth amongst Iranian childbearing women: a qualitative study. BMC Pregnancy and Childbirth, v. 20, p. 1-9, 2020.

TRINDADE, J. Manual de psicologia jurídica para operadores do direito. 8. ed. Porto Alegre: Livro do Advogado, 2017.

WISE, E. A. Psychological Injuries, Workers' Compensation Insurance, and Mental Health Policy Issues. Psychological Injury and Law, v. 9, n. 4, p. 283-297, 2016. 
XIMENES, L. F.; OLIVEIRA, R. de V. C. de; ASSIS, S. G. de. Violência e transtorno de estresse pós-traumático na infância. Ciência \& Saúde Coletiva, v. 14, p. 417-433, 2009.

Recebido em: 05/01/2022

Aprovado em: 08/02/2022

Publicado em: 11/02/2022 